\title{
Effect of p27 on motility of MDA-MB-231 breast cancer cells
}

\author{
EUN YOUNG LEE ${ }^{1}$, MIN JEONG JEON ${ }^{2}$, WONSEOK YANG ${ }^{2}$ and INCHEOL SHIN ${ }^{1,2}$ \\ Departments of ${ }^{1}$ Biology Education and ${ }^{2}$ Life Science, College of Natural Sciences, \\ Hanyang University, Seoul 133-791, Korea
}

Received January 30, 2009; Accepted March 23, 2009

DOI: 10.3892/or_00000396

\begin{abstract}
Kip family of cyclindependent kinase inhibitors and its overexpression results in cell cycle arrest at G1 and/or apoptosis. In addition to its role as a regulator of cell cycle progression, p27 can also participate in cell motility, especially when it is mislocalized in the cytosol. To further elucidate the role of p27 in the motility of MDA-MB-231 breast cancer cells, we performed p27 knockdown in MDA-MB-231 cells by RNA interference. Infection of MDA-MB-231 cells with retroviruses harboring p27 short hairpin RNA (shRNA) designed from human p27 cDNA resulted in efficient inhibition of p27 expression, while p27 shRNA designed from mouse p27 cDNA did not affect p27 expression in MDA-MB-231 cells. MDA-MB-231 cells infected with human p27 shRNA (MDA-MB-231 hp27shRNA) showed increased proliferation compared to control MDA-MB-231 cells and MDA-MB-231 cells infected with mouse p27shRNA (MDA-MB-231 mp27shRNA). Wound healing assays revealed that migration of MDAMB-231 hpshRNA cells was markedly impaired compared to MDA-MB-231 mpshRNA cells, especially when cycloheximide was added to block protein synthesis. Immunostaining of p27 in MDA-MB-231 cells showed that p27 predominantly localized in the nuclei. These results suggest that both nuclear and cytosolic p27 can promote cancer cell motility.
\end{abstract}

\section{Introduction}

Cyclin/cyclin-dependent kinase (Cdk) complexes are pivotal in regulating cell cycle progression (1). A group of proteins known as $\mathrm{Cdk}$ inhibitors regulate cyclin/Cdk complexes, including the Cip/Kip proteins (p21, p27 and p57) and the Ink proteins (p15, p16, p18, p19). Protein levels of p27, a negative regulator of cell cycle progression, are inversely correlated with cancer patient survival (2). Along with protein level, the

Correspondence to: Dr Incheol Shin, Department of Life Science, College of Natural Sciences, Hanyang University, Seoul 133-791, Korea

E-mail: incheol@hanyang.ac.kr

Key words: breast cancer, cell motility, p27 intracellular compartmentalization of p27 is also important during cell cycle progression. For the efficient inhibition of cyclinE/Cdk2, p27 must be localized in the nucleus (3). In the $\mathrm{G} 0 / \mathrm{G} 1$ phase of the cell cycle, p27 is almost exclusively localized in the nucleus, but a significant pool of p27 is translocated to the cytosol in response to mitogenic stimulation (4). Inhibition of Cdks by direct binding of p27 in the nucleus might be impaired in many human tumor cells where cytosolic localization of p27 is observed (5-7). Cytosolic localization of p27 can be achieved by subsequent phosphorylation of Ser10 and Thr157 by growth factor-dependent human kinaseinteracting stathmin and Akt, respectively $(4,8,9)$.

Certain lines of evidence suggest that p27 may have an additional role as a regulator of cell movement, especially when translocated to the cytosol. Delivery of TAT-p27 fusion protein into hepatoma cells leads to increased cell migration (10). In the developing mouse embryo, two kip-type Cdk inhibitors, p27 and p57, play essential roles in neuronal migration (11). Wu et al (12) showed that knockdown of cytosolic p27 inhibits motility of U87 glioma cells.

In this study, we report that short hairpin RNA (shRNA)mediated knock-out of p27 in MDA-MB-231 breast cancer cells led to enhanced cell proliferation and decreased migration. Immunostaining of p27 and subcellular fractionation assays using MDA-MB-231 cells revealed that p27 of MDAMB-231 cells is predominantly localized in the nucleus, suggesting that nuclear p27 is also responsible for cancer cell movement.

\section{Materials and methods}

Generation of MDA-MB-231hp27shRNA cells. The MDAMB-231 human breast cancer cell line was obtained from the ATCC, pSUPER.retro vectors harboring shRNAs against human p27 and mouse p27 were kindly provided by Dr Carlos Arteaga (Vanderbilt University). Retroviruses were prepared by transfection of 293T cells with $15 \mu \mathrm{g}$ DNA/ $100 \mathrm{~mm}$ dish of three plasmids encoding gag/pol, VSV-G, and pSUPER-hp27 shRNA or pSUPER-mp27 shRNA, at the mass ratio of $4: 3: 8$. Supernatants from cells were collected for 3 days, combined, filtered through $0.4 \mu \mathrm{m}$ filters and stored in aliquots at $-80^{\circ} \mathrm{C}$. Supernatants containing retroviral particles were applied to MDA-MB-231 cells in the presence of $6 \mu \mathrm{g} / \mathrm{ml}$ polybrene (Sigma). Three days later, the infected cells were selected by $1 \mu \mathrm{g} / \mathrm{ml}$ puromycin (Gibco) treatment. The surviving colonies were isolated and their p27 expression levels were checked by Western blot analyses. The cells were 
then maintained in DMEM (Gibco) supplemented with $10 \%$ fetal bovine serum (Gibco) at $37^{\circ} \mathrm{C}$ under $5 \% \mathrm{CO}_{2}$.

Western blot analyses. MDA-MB-231, MDA-MB-231 mp27shRNA and MDA-MB-231 hp27shRNA cells were washed once with phosphate-buffered saline (PBS) and lysed with a lysis buffer [20 mM Tris- $\mathrm{HCl}, \mathrm{pH} 7.4,0.1 \mathrm{mM}$ EDTA, $150 \mathrm{mM} \mathrm{NaCl}, 1 \% \mathrm{NP}-40,0.1 \%$ Triton $\mathrm{X}-100,0.1 \%$ SDS, $20 \mathrm{mM} \mathrm{NaF}, 1 \mathrm{mM} \mathrm{Na} \mathrm{VO}_{4}, 1 \mathrm{X}$ protease inhibitor (Roche)]. All protein samples were resolved by $10 \%$ SDS-PAGE after boiling for $5 \mathrm{~min}$ in SDS sample buffer. The protein bands were transferred onto nitrocellulose membranes in Trisglycine-methanol buffer and visualized with appropriate primary antibodies followed by HRP-conjugated secondary antibody (Amersham) and the WEST-ZOL ${ }^{\circledR}$ plus Western blot detection system (iNtRON). The primary antibodies were all purchased from Santa Cruz Biotechnologies.

Proliferation assays. MDA-MB-231, MDA-MB-231 mp27shRNA and MDA-MB-231 hp27shRNA cells were seeded onto 12 -well plates at a density of $1 \times 10^{4}$ cells/well. Cells were counted using a hematocytometer after $24,48,72$ and $96 \mathrm{~h}$.

Wound healing assays. MDA-MB-231 mp27shRNA and MDA-MB-231 hp27shRNA cells were seeded in 6-well plates at a density of $1 \times 10^{4}$ cells/well. After three days, wounds were made by scraping across the confluent cell monolayer with a plastic pipette tip. Assays were carried out in the absence and presence of $0.28 \mu \mathrm{g} / \mathrm{ml}$ cycloheximide (Sigma) to block protein synthesis. Phase contrast microscopic images were recorded at the time of wounding $(0 \mathrm{~h})$, and after 20, 30 and $48 \mathrm{~h}$. Wound closure was estimated as the percentage of the remaining wound area relative to the initial wound area. Experiments were repeated more than 3 times.

Immunostaining. MDA-MB-231, MDA-MB-231 mp27shRNA and MDA-MB-231 hp27shRNA cells seeded on glass coverslips in 6-well plates were washed with PBS, fixed with $3.8 \%$ paraformaldehyde in PBS for $10 \mathrm{~min}$ and permeabilized with $0.05 \%$ Triton $\mathrm{X}-100$ in PBS for $10 \mathrm{~min}$ at ambient temperature. The fixed cells were washed 3 times with PBS for 5 min each and blocked with 3\% skim milk in PBS for $30 \mathrm{~min}$. Anti-p27 primary antibody (Santa Cruz) solution $(80 \mu 1)$ diluted in $1 \%$ skim milk in PBS was added per coverslip and incubated for $1 \mathrm{~h}$. Cells were washed 3 times with PBS and then incubated with $80 \mu 1$ of secondary antibody solution [anti-rabbit IgG-Oregon Green (Molecular Probe)]. Cells were washed 3 times for $10 \mathrm{~min}$ with PBS, and then nuclei were counter-stained with $1 \mu \mathrm{g} / \mathrm{ml}$ Hoechst for $10 \mathrm{~min}$ at ambient temperature. Coverslips were mounted on $25 \times 75 \mathrm{~mm}$ microslides (VWR Scientific) using AquaPolyMount (Polysciences), Fluorescent images were captured using a fluorescence microscope (Olympus BX50).

Cell fractionation. MDA-MB-231 mp27shRNA cells seeded at a density of $1 \times 10^{6}$ cells per $100-\mathrm{mm}$ dish were harvested in cytoplasmic extraction buffer (10 mM HEPES; pH 7.9, $10 \mathrm{mM} \mathrm{KCl}, 0.1 \mathrm{mM}$ EDTA, $0.1 \mathrm{mM}$ EGTA, $1 \mathrm{mM}$ DTT, $0.5 \mathrm{mM}$ PMSF) and agitated for $10 \mathrm{~min}$ at $4^{\circ} \mathrm{C}$. The samples

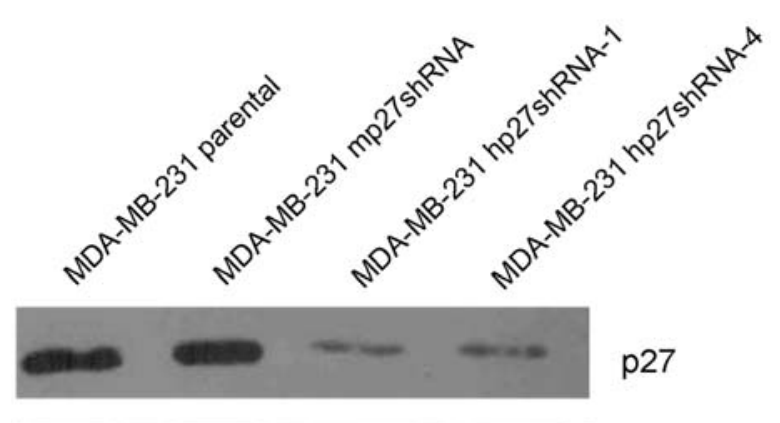

Ponceau staining

Figure 1. Silencing of p27 in MDA-MB-231 cells by retroviral infection of shRNA. MDA-MB-231 cells were infected with retroviruses encoding shRNA against mouse p27 and human p27 (Materials and methods). After several days, the infected cells were selected using puromycin. The silencing of p27 was confirmed by Western blot analyses. Ponceau staining of the proteins on nitrocellulose membranes was used to confirm the even levels of protein in each lane.

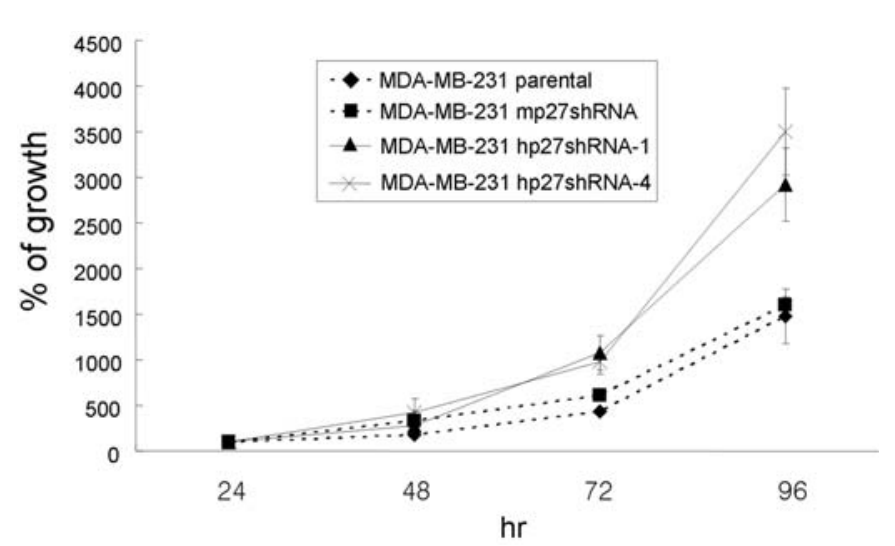

Figure 2. Effect of p27 silencing on proliferation of MDA-MB-231 cells. Cells were seeded as indicated in Materials and methods and counted with a hematocytometer at each indicated time point. •, MDA-MB-231 parental cells; $\boldsymbol{-}$, MDA-MB-231 mp27shRNA; $\Delta$, MDA-MB-231 hp27shRNA-1; x, MDA-MB-231 hp27shRNA-4.

were then subjected to centrifugation at $13,000 \mathrm{rpm}$ in a microcentrifuge (Eppendorf) for $5 \mathrm{~min}$. The supernatants were collected as the cytosolic fraction. The nuclear pellets were washed 2 times with cold PBS and resuspended in a nuclear extraction buffer (20 mM HEPES; pH 7.9, $400 \mathrm{mM}$ $\mathrm{NaCl}, 1 \mathrm{mM}$ EDTA, $1 \mathrm{mM}$ EGTA, $1 \mathrm{mM}$ DTT, $1 \mathrm{mM}$ PMSF). Nuclear extracts were agitated for $10 \mathrm{~min}$ at $4^{\circ} \mathrm{C}$ and centrifuged at $13,000 \mathrm{rpm}$ at $4^{\circ} \mathrm{C}$. The resulting supernatants were collected as the nuclear fraction.

\section{Results}

Effect of p27 silencing on proliferation of MDA-MB-231 cells. After infection of MDA-MB-231 cells with retroviral particles harboring shRNA against human p27 and mouse p27, cultures were treated with puromycin to select the virusinfected cells. Two clones (MDA-MB-231 hp27shRNA-1 and MDA-MB-231 hp27shRNA-4 cells) exhibited decreased expression of p27 as compared to parental MDA-MB-231 

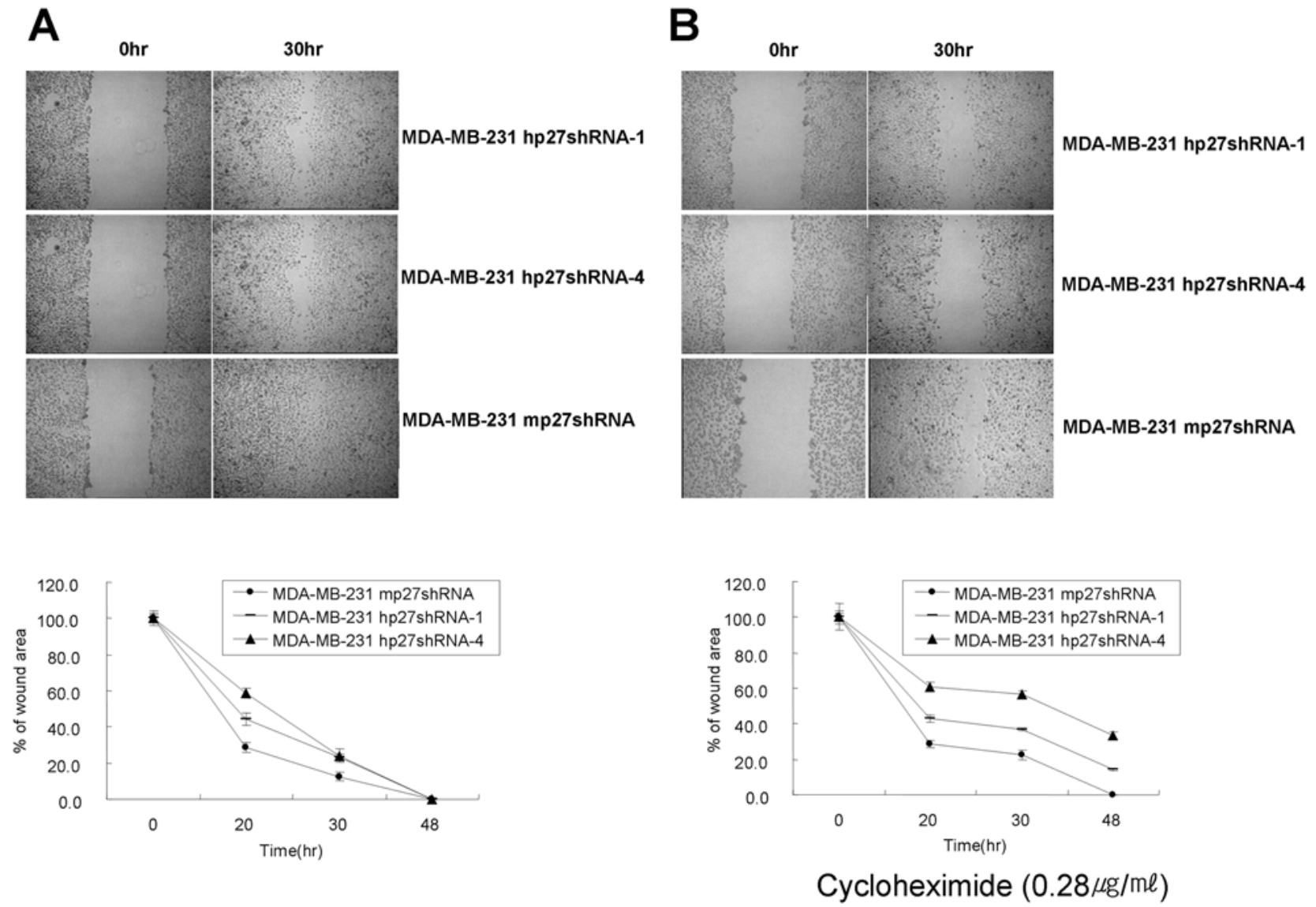

Figure 3. Effect of p27 silencing on motility of MDA-MB-231 cells. Wound healing assays were performed as described in Materials and methods both in the presence (A) and absence (B) of $0.28 \mu \mathrm{g} / \mathrm{ml}$ cycloheximide. At each indicated time point after wound formation, the width of the wounded area was measured and expressed as a percentage of the original width of the wound. Three independent experiments were performed and the mean \pm SD was plotted.

cells and mouse (control) p27 shRNA infected MDA-MB$231 \mathrm{mp} 27 \mathrm{shRNA}$ cells (Fig. 1). Since p27 can regulate cell proliferation via blockade of the $\mathrm{G} 1$ to $\mathrm{S}$ transition of the cell cycle (3), we examined the effect of p27 silencing on proliferation of MDA-MB-231 cells. Both MDA-MB-231 hp27shRNA-1 and MDA-MB-231 hp27shRNA-4 cells exhibited efficient increases in cell proliferation compared to parental MDA-MB-231 cells and control MDA-MB-231 mp27shRNA cells (Fig. 2). Proliferation of MDA-MB-231 hp27shRNA-4 cells particularly increased $\sim 3.3$-fold by 4 days after the seeding. These results suggest that silencing of p27 effectively enhanced proliferation of MDA-MB-231 breast cancer cells.

p27 silencing impaired the motility of MDA-MB-231 cells. Since p27 can regulate the motility of cancer cells $(12,13)$, we examined the effect of p27 silencing on the motility of MDA-MB-231 cells using wound healing assays. Because silencing of p27 could enhance the proliferation rate of MDA-MB-231 cells (as indicated in Fig. 2), wound healing assays were performed in the absence (Fig. 3A) and presence (Fig. 3B) of cycloheximide, which inhibits protein synthesis by blocking the peptidyl transferase activity of ribosomes (14). Treatment with cycloheximide blocked proliferation of MDA-MB-231 cells at a concentration of $0.28 \mu \mathrm{g} / \mathrm{ml}$ (data not shown). Silencing of p27 by shRNA inhibited wound closure most efficiently at $20 \mathrm{~h}$ after wound formation in the absence of cycloheximide (Fig. 3). Even so, the wounded areas were all closed in all three cell lines after $48 \mathrm{~h}$. When cultures were treated with cycloheximide to block cell proliferation, MDA-MB-231 mp27shRNA cells migrated into the wounded area and closed the wound within $48 \mathrm{~h}$. In the MDA-MB-231 hp27shRNA clones, the wound remained open at $48 \mathrm{~h}$ (Fig. 3B). These data suggest that silencing of p27 abrogated motility of the MDA-MB-231 cells.

Subcellular localization of p27 in MDA-MB-231 cells. The next step was to determine the subcellular distribution of p27 in MDA-MB-231 cells, since cytosolic p27 can inhibit RhoA activation and induce cell motility (12). Immunostaining revealed that p27 was predominantly localized in the nucleus in both parental MDA-MB-231 cells and MDA-MB-231 mp27shRNA cells (Fig. 4A). In accordance with the Western blot results (Fig. 1), immunoreactive p27 was not observed in either MDA-MB-231 hp27shRNA-1 or MDA-MB-231 hp27shRNA-4 cells. Subcellular fractionation indicated that the majority of p27 in MDA-MB-231 mp27shRNA cells was in the nucleus (Fig. 4B). Collectively, our results suggest that nuclear p27 was responsible for the migration of MDA-MB-231 cells.

\section{Discussion}

We examined the effect of p27 silencing on the proliferation and motility of MDA-MB-231 breast cancer cells. Silencing 

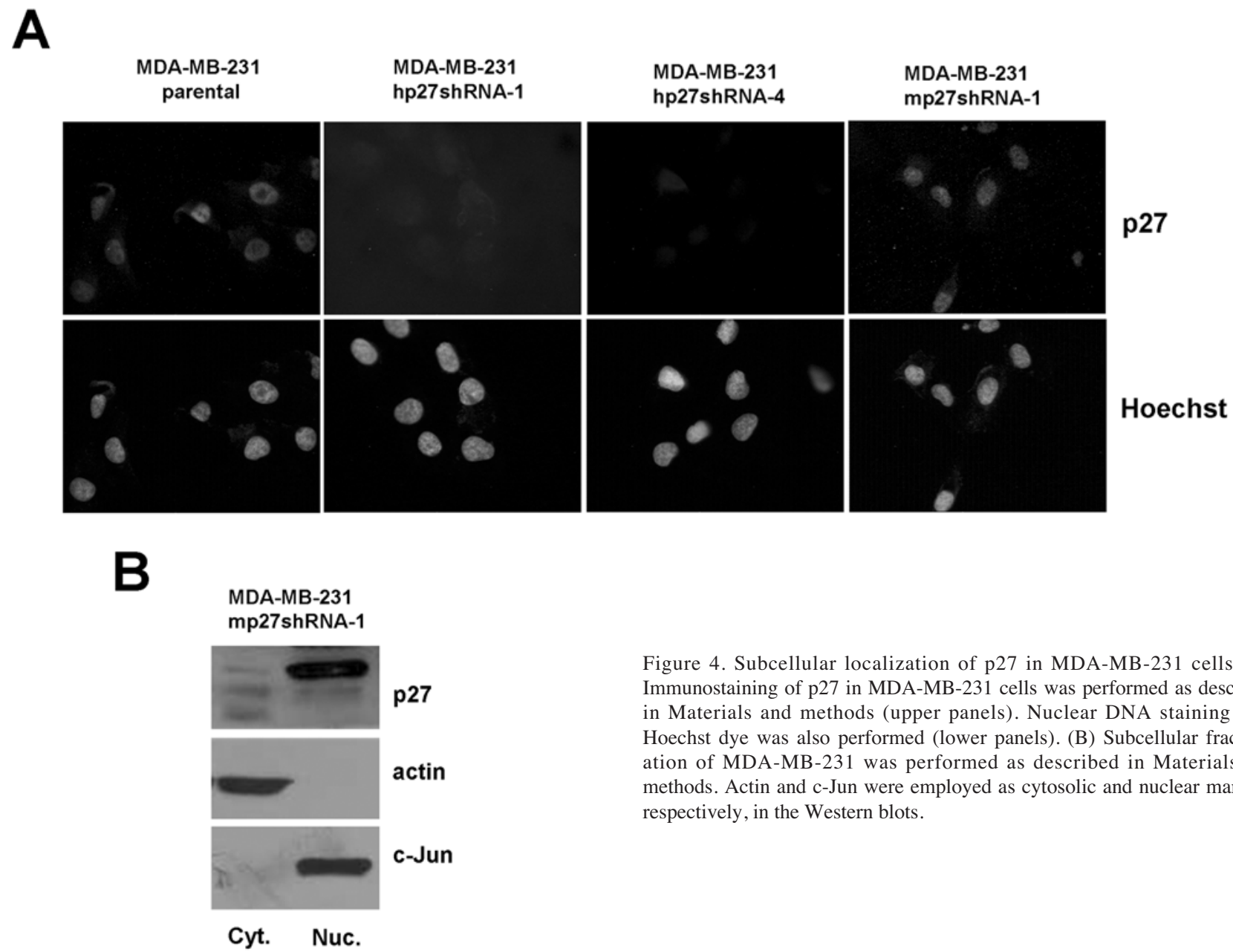

of p27 by retroviral delivery of shRNA against p27 increased proliferation of MDA-MB-231 cells and decreased the motility of the cells. p27 was initially discovered as a Cdk inhibitor induced by mitogenic signals from outside the cells (1). Multiple lines of experimental evidence suggest that partial loss or mislocalization of $\mathrm{p} 27$ to the cytoplasm is responsible for increased transformation $(9,15,16)$. Total loss of $p 27$ alleles may interfere with tumorigenesis, since homozygous deletions of the p27 gene are extremely rare in human cancers (17). Although the modulation of cell mobility by p27 (independent of Cdk inhibition) has been reported, it remains controversial whether p27 promotes or inhibits cell migration. For example, high levels of p27 and p27 phosphorylated at Ser10, which is responsible for the cytosolic localization of p27 (18), are detected in metastatic hepatocellular carcinoma cells, but not non-metastatic hepatocellular carcinoma cells (13). p27 knockdown by RNA interference increases RhoA activity and stress fiber formation and decreases cell migration, suggesting that p27 promotes metastatic hepatocellular carcinoma cells through modulation of RhoA (13).

$\mathrm{Wu}$ et al (12) reported that RNA interference-induced suppression of p27 in U87MG glioma cells with $>50 \%$ expression of cytosolic p27 expression leads to markedly impaired motility in transwell migration assays. Using the same retroviral vector for RNA interference, they have also shown that motility of COS7 cells with exclusive nuclear p27 localization is moderately affected by $\mathrm{p} 27$ silencing, indicating that cytoplasmic p27 is mainly responsible for the modulation

Figure 4. Subcellular localization of p27 in MDA-MB-231 cells. (A) Immunostaining of p27 in MDA-MB-231 cells was performed as described in Materials and methods (upper panels). Nuclear DNA staining with Hoechst dye was also performed (lower panels). (B) Subcellular fractionation of MDA-MB-231 was performed as described in Materials and methods. Actin and c-Jun were employed as cytosolic and nuclear markers, respectively, in the Western blots.

of cell motility. In contrast, Schiappacassi et al (19) recently reported that cytoplasmic p27 inhibits motility of U87MG glioma cells through its carboxy-teminal portion. Analyzing the effect of cytoplasmic p27 on cell proliferation rate and migration rate using $\mathrm{T} 98 \mathrm{G}$ and $\mathrm{U} 138$ glioma cells (strong cytoplasmic p27 expression) and U87MG and SF268 glioma cells (low cytoplasmic p27 levels), they found no direct correlation between cytoplasmic p27 levels and proliferation rates, and that cells with strong p27 cytoplasmic expression exhibited a decreased migration rate through extracellular matrices. A study using estrogen-dependent T47D breast cancer cells also showed that loss of p27 increases cell migration and invasion (20).

Although there are mixed opinions about the role of p27 in the motility of cancer cells, it is now generally believed that p27 has both tumor suppressive and oncogenic functions (21). Animals heterozygous for p27 are more susceptible to mammary and prostate tumors than p27 null animals $(15,16)$, indicating that one allele of p27 is actively involved in turmorigenesis. Recently, Besson et al (22) reported that a knock-in mouse model expressing a mutant p27 unable to interact with cyclins and Cdks develops hyperplastic lesions and tumors in multiple organs including the lung, retina, pituitary, and ovary. They also showed that mutant p27 expression in these animals leads to amplification of stem/progenitor cell populations in lung and retina tumors. This oncogenic function of p27 may help to explain the fact that the loss of one p27 allele leads to partial down-regulation of tumor suppressive cyclin/Cdk 
inhibitory activity while maintaining the tumorigenic activity of $\mathrm{p} 27$.

Nuclear localization of p27 is required to inhibit $\mathrm{Cdk}$ activation by Cdk-activating kinase $(3,23)$. Hence the cellcycle regulatory activity of p 27 is regulated by changes in the p27 protein quantity and nuclear localization of p27. The phosphorylation of Ser10, Thr157 and Thr198 on p27 is required to promote cytosolic export of p27 $(4,8,24)$. The cell cycle-independent functions of p27 were first found using TAT-p27 fusion protein transduction into HepG2 cells, which demonstrated that $\mathrm{p} 27$ can promote cell migration and scattering (10). Later, the same group reported that the cell migratory activity of p27 occurs independent of its cell cycle arrest functions, and that it requires cytoplasmic localization of p27 and Rac GTPase (25). Furthermore, mouse embryonic fibroblasts (MEFs) derived from p27-null mice exhibit a dramatic decrease in motility compared to wild-type cells, and this effect of p27 on cell migration is mediated via modulation of the Rho signaling pathway (26).

$\mathrm{Wu}$ et al (12) have also reported that cytosolic p27 downregulates RhoA and increases cell motility. Since RhoA is predominantly localized in the plasma membrane and cytosol (27), the interaction between RhoA and p27 was thought to preferentially occur in the cytoplasm. However, the re-expression of p27 in p27-null MEFs revealed that most of the ectopically expressed p27 remains nuclear while inhibiting cytosolic stress fiber formation, which is absolutely dependent on RhoA activity $(26,27)$. We also found that the majority of p27 in MDA-MB-231 cells was localized in the nucleus (Fig. 4). Although we can not completely rule out the possibility that a minimum level of cytosolic p27 in MDAMB-231 cells might be responsible for p27-dependent motility, our data suggest that nuclear p27 contributes to the motility of cancer cells. A recent study (28) describes finding a significant portion of RhoA in the nucleus of gastric cancer cells. Taking these findings together, we propose that both nuclear and cytosolic p27 may regulate the motility of cancer cells. The involvement of RhoA in the modulation of cell motility by nuclear p27 warrants further investigation.

\section{Acknowledgements}

This work was supported by the research fund of Hanyang University (HY-2005-N).

\section{References}

1. Sherr CJ: Cancer cell cycles. Science 274: 1672-1677, 1996.

2. Reed SI: Keeping p27(Kip1) in the cytoplasm: a second front in cancer's war on p27. Cell Cycle 1: 389-390, 2002.

3. Reynisdottir I and Massague J: The subcellular locations of p15(Ink4b) and p27(Kip1) coordinate their inhibitory interactions with cdk4 and cdk2. Genes Dev 11: 492-503, 1997.

4. Shin I, Rotty J, Wu FY and Arteaga CL: Phosphorylation of p27Kip1 at Thr-157 interferes with its association with importin alpha during G1 and prevents nuclear re-entry. J Biol Chem 280: 6055-6063, 2005 .

5. Orend G, Hunter T and Ruoslahti E: Cytoplasmic displacement of cyclin E-cdk2 inhibitors p21Cip1 and p27Kip1 in anchorageindependent cells. Oncogene 16: 2575-2583, 1998.

6. Ciaparrone M, Yamamoto H, Yao Y, Sgambato A, Cattoretti G, Tomita N, et al: Localization and expression of p27KIP1 in multistage colorectal carcinogenesis. Cancer Res 58: 114-122, 1998.
7. Singh SP, Lipman J, Goldman H, Ellis FH Jr, Aizenman L, Cangi MG, et al: Loss or altered subcellular localization of p27 in Barrett's associated adenocarcinoma. Cancer Res 58: 1730-1735, 1998.

8. Boehm M, Yoshimoto T, Crook MF, Nallamshetty S, True A, Nabel GJ, et al: A growth factor-dependent nuclear kinase phosphorylates p27(Kip1) and regulates cell cycle progression. EMBO J 21: 3390-3401, 2002.

9. Shin I, Yakes FM, Rojo F, Shin NY, Bakin AV, Baselga J, et al: $\mathrm{PKB} / \mathrm{Akt}$ mediates cell-cycle progression by phosphorylation of p27(Kip1) at threonine 157 and modulation of its cellular localization. Nat Med 8: 1145-1152, 2002.

10. Nagahara H, Vocero-Akbani AM, Snyder EL, Ho A, Latham DG, Lissy NA, et al: Transduction of full-length TAT fusion proteins into mammalian cells: TAT-p27Kip1 induces cell migration. Nat Med 4: 1449-1452, 1998.

11. Itoh Y, Masuyama N, Nakayama K, Nakayama KI and Gotoh Y: The cyclin-dependent kinase inhibitors p57 and p27 regulate neuronal migration in the developing mouse neocortex. J Biol Chem 282: 390-396, 2007.

12. Wu FY, Wang SE, Sanders ME, Shin I, Rojo F, Baselga J, et al: Reduction of cytosolic p27(Kip1) inhibits cancer cell motility, survival, and tumorigenicity. Cancer Res 66: 2162-2172, 2006.

13. Wang XQ, Lui EL, Cai Q, Ching WY, Liu KS, Poon RT, et al: p27Kip1 promotes migration of metastatic hepatocellular carcinoma cells. Tumour Biol 29: 217-223 2008.

14. Baliga BS, Pronczuk AW and Munro HN: Mechanism of cycloheximide inhibition of protein synthesis in a cell-free system prepared from rat liver. J Biol Chem 244: 4480-4489, 1969.

15. Muraoka RS, Lenferink AE, Law B, Hamilton E, Brantley DM, Roebuck LR, et al: ErbB2/Neu-induced, cyclin D1-dependent transformation is accelerated in p27-haploinsufficient mammary epithelial cells but impaired in p27-null cells. Mol Cell Biol 22: 2204-2219, 2002

16. Gao H, Ouyang X, Banach-Petrosky W, Borowsky AD, Lin Y, Kim M, et al: A critical role for p27kip1 gene dosage in a mouse model of prostate carcinogenesis. Proc Natl Acad Sci USA 101: 17204-17209, 2004.

17. Philipp-Staheli J, Payne SR and Kemp CJ: p27(Kip1): regulation and function of a haploinsufficient tumor suppressor and its misregulation in cancer. Exp Cell Res 264: 148-168, 2001.

18. Rodier G, Montagnoli A, Di Marcotullio L, Coulombe P, Draetta GF, Pagano M, et al: p27 cytoplasmic localization is regulated by phosphorylation on Ser10 and is not a prerequisite for its proteolysis. EMBO J 20: 6672-6682, 2001.

19. Schiappacassi M, Lovat F, Canzonieri V, Belletti B, Berton S, Di Stefano D, et al: p27Kip1 expression inhibits glioblastoma growth, invasion, and tumor-induced neoangiogenesis. Mol Cancer Ther 7: 1164-1175, 2008.

20. Yuan Y, Qin L, Liu D, Wu RC, Mussi P, Zhou S, et al: Genetic screening reveals an essential role of p27kip1 in restriction of breast cancer progression. Cancer Res 67: 8032-8042, 2007.

21. Sicinski P, Zacharek S and Kim C: Duality of p27Kip1 function in tumorigenesis. Genes Dev 21: 1703-1706, 2007.

22. Besson A, Hwang HC, Cicero S, Donovan SL, Gurian-West M, Johnson D, et al: Discovery of an oncogenic activity in p27Kip1 that causes stem cell expansion and a multiple tumor phenotype. Genes Dev 21: 1731-1746, 2007.

23. Darbon JM, Devault A, Taviaux S, Fesquet D, Martinez AM, Galas S, et al: Cloning, expression and subcellular localization of the human homolog of p40MO15 catalytic subunit of cdkactivating kinase. Oncogene 9: 3127-3138, 1994.

24. Fujita N, Sato S, Katayama K and Tsuruo T: Akt-dependent phosphorylation of $\mathrm{p} 27 \mathrm{Kip} 1$ promotes binding to 14-3-3 and cytoplasmic localization. J Biol Chem 277: 28706-28713, 2002.

25. McAllister SS, Becker-Hapak M, Pintucci G, Pagano M and Dowdy SF: Novel p27(kip1) C-terminal scatter domain mediates Rac-dependent cell migration independent of cell cycle arrest functions. Mol Cell Biol 23: 216-228, 2003.

26. Besson A, Gurian-West M, Schmidt A, Hall A and Roberts JM: p27Kip 1 modulates cell migration through the regulation of RhoA activation. Genes Dev 18: 862-876, 2004.

27. Hall A: Rho GTPases and the actin cytoskeleton. Science 279: 509-514, 1998.

28. Tao Y, Chen YC, Li YY, Yang SQ and Xu WR: Localization and translocation of RhoA protein in the human gastric cancer cell line SGC-7901. World J Gastroenterol 14: 1175-1181, 2008. 